\title{
Function of ribosomes and glutamyl-tRNA isoacceptors in protein synthesis in regenerating skeletal muscle
}

\author{
George H. Jones \\ Department of Cellular and Molecular Biology, Division of Biological Sciences, The University of Michigan, Ann Arbor, \\ MI 48109-1048 (U.S.A.)
}

(Received November 7th, 1984)

Key words: Ribosome; tRNA isoacceptor; glutamyl-tRNA; Protein synthesis; (Rat skeletal muscle)

Ribosomes from 8-day-regenerating rat skeletal muscle have been shown to be more active in poly(U)-directed polyphenylalanine synthesis than ribosomes from control muscle. This difference persists after salt washing of the ribosomes and does not appear to be due to the presence of ribonuclease associated with the control ribosome population. Ribosomes from control muscle were also less active than those from regenerates in the nonenzymatic binding of phenylalanyl-tRNA to ribosomes and in the peptidyltransferase reaction. Three glutamyl-tRNA isoacceptors have been isolated from 8-day-regenerating rat skeletal muscle

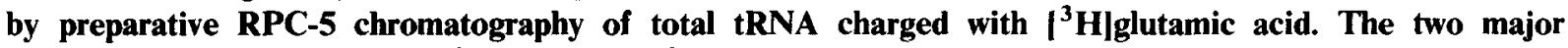
isoacceptors observed, tRNA glu and tRNA III, respond to the glutamic acid codons GAG and GAA, respectively. A third, minor glutamyl isoacceptor, tRNA $\}_{l}^{\text {lu }}$, also responds to the codon GAA. When the three isoacceptors were tested for function in a polysomal cell-free protein synthesizing system, it was found that their relative levels of utilization were essentially identical to their relative abundances. Thus, the tRNA which increases in relative amount after the induction of regeneration, tRNA II $_{\mathrm{l}}$, is not preferentially utilized for overall muscle protein synthesis.

Marcaine (bupivacaine) is a myotoxic drug which has been useful in the study of skeletal muscle regeneration. It has been shown by HallCraggs [1], by Carlson and co-workers [2] and by others $[3,4]$ that the injection of the drug leads to a rapid degeneration of rat skeletal muscle followed by a synchronous regeneration process. Recent studies from the author's laboratory have been directed toward the changes in protein synthesis which accompany Marcaine-induced regeneration of rat tibialis anterior. It has been shown that there is an initial increase in the concentration and activity of polyribosomes in regenerating muscle as compared to controls [5] and that there are changes in the amino acid acceptor activities, isoacceptor profiles and function in protein synthesis of transfer RNAs from regenerating muscle as compared with controls [6]. The observed changes in parameters associated with the translational apparatus are greatest during the early stages of the regeneration process (5-8 days post-injection) and the values return to near control levels by 30 days following Marcaine injection, at which time regeneration is essentially complete $[5,6]$.

In view of the possible involvement of the observed translational changes in the synthesis of the myofibrillar proteins required for muscle regeneration, it is of interest to examine further the molecular mechanisms responsible for those alterations. To this end, the function of ribosomes from control and regenerating tibialis has been compared. Ribosomes have been tested in a poly(U)-dependent protein synthesizing system, for their ability to support the binding of aminoacyl-tRNA, and in 
the peptidyltransferase reaction. In addition, the function of the three glutamyl-tRNA isoacceptors, whose relative proportions change during regeneration, has been tested in a polysomal protein synthesizing system. Results of these studies are presented below.

\section{Materials and Methods}

Materials. Adult male Sprague-Dawley rats were used in all experiments. Sources and specific activities of radioactive amino acids were as indicated previously [6].

Marcaine injection procedure. Rats were injected with $0.75 \%$ Marcaine in one tibialis muscle as described previously $[5,6]$. The contralateral muscle served as a control and was injected with saline only. Muscles were generally removed 8 days following injection, as changes in the translational apparatus were maximal at this time point $[5,6]$.

Preparation of components for cell-free translation. Procedures for the preparation of polyribosomes, transfer RNAs (from both muscle and rat liver) and soluble enzymes were exactly as described previouly $[5,6]$. Total ribosomes were obtained from control and regenerating muscle as described in ref. 7 , except that cycloheximide and the sucrose cushion were omitted. Salt-washed ribosomes were obtained as described previously [8].

Conditions for cell-free protein synthesis, aminocylation of $t R N A$, aminoacyl-tRNA binding and peptidyltransferase assay. Conditions for cell-free protein synthesis were as described previously $[5,6]$, except that reaction mixtures contained $0.3 \mathrm{mg} / \mathrm{ml}$ poly $(\mathrm{U}), 5 \mu \mathrm{Ci} / \mathrm{ml}\left[{ }^{14} \mathrm{C}\right.$ ) units $/ \mathrm{ml}$ human placental ribonuclease inhibitor (RNAse inhibitor). Conditions for polysomal protein synthesis using [ ${ }^{3} \mathrm{H}$ ]glutamyl-isoacceptors were as described in Ref. 6 and in the legend to Table IV.

Muscle tRNA was acylated with $\left[{ }^{3} \mathrm{H}\right]$ phenylalanine, $\left[{ }^{14} \mathrm{C}\right]-$ or $\left[{ }^{3} \mathrm{H}\right]$ glutamic acid as described previously [6]. Glutamyl-tRNA isoacceptors were fractionated by RPC-5 chromatography as indicated in Ref. 6 and in the legend to Fig. 2. Individual isoacceptors were isolated by ethanol precipitation of appropriate column fractions. $N$ acetyl $\left[{ }^{3} \mathrm{H}\right]$ phenylalanyl-tRNA was prepared as de- scribed by Haenni and Chapeville [9].

Binding of aminoacyl-tRNAs to ribosomes was carried out according to Nirenberg and Leder [10]. In some experiments, binding mixtures were supplemented with soluble enzymes at $8 \mathrm{mg}$ protein per $\mathrm{ml}$. To determine the codon responses of the glutamyl-tRNA isoacceptors, reaction mixtures contained the trinucleotide codon GAA or GAG (kindly supplied by Dr. Dolph Hatfield, National Cancer Institute). Other reaction conditions are indicated in the legends to Tables II and III.

The peptidyltransferase assay was performed following binding of $N$-acetyl[ $\left[{ }^{3} \mathrm{H}\right]$ phe-tRNA to muscle ribosomes [10] in the presence of poly(U) and soluble enzymes as described above. After a $15 \mathrm{~min}$ incubation at $37^{\circ} \mathrm{C}, 10 \mu 1$ of $10 \mathrm{mM}$ puromycin was added to each $100 \mu 1$ reaction mixture. Incubation was continued for $15 \mathrm{~min}$ when $0.1 \mathrm{ml}$ of $1 \mathrm{M} \mathrm{KOH}$ was added. Reaction mixtures were then extracted with $1 \mathrm{ml}$ of ethyl acetate, and 200- $\mu 1$ aliquots of each extract were examined by liquid scintillation counting.

\section{Results}

Function of muscle ribosomes in poly(U)-dependent protein synthesis

In a previous report, evidence was provided for an increase in the activity of polyribosomes from regenerating as compared with control skeletal muscle [5]. The data of Fig. 1 show that this

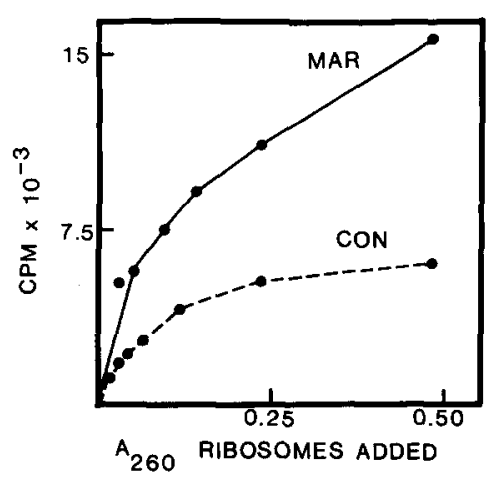

Fig. 1. Effects of ribosome concentration on the incorporation of $\left[{ }^{14} \mathrm{C}\right]$ phenylalanine in a cell-free system. Reaction conditions were as specified in Materials and Methods and in Refs. 5 and 6. Ribosomes were isolated from control tibialis and from 8-day-regenerating tibialis. CON, control; MAR, Marcainetreated. 
phenomenon persists when total ribosomes are isolated and tested in a cell-free system primed with a synthetic mRNA. It can be observed that ribosomes from 8-day regenerates were over twice as active (per unit of ribosomes added) in polyphenylalanine synthesis as were ribosomes from control muscle. Since the soluble enzymes used in these experiments were obtained from rat liver, the ribosomes, or factor associated with them, must be responsible for the differences depicted in Fig. 1.

It was of further interest to determine whether the differences described above could be eliminated by salt washing of the ribosomes from control and regenerating muscle. When once-salt-washed ribosomes were tested in cell-free protein synthesis the results shown in Table I were obtained. Although salt washing did result in a decrease in the activity of both control ribosomes and ribosomes from 8-day regenerates, it is clear from Table I that the difference in activity between the two ribosome populations persists after washing. Thus, the difference cannot be due to protein factors which are only loosely associated with the ribosomes in question. Table I also eliminates ribonuclease as the source of the activity difference observed. Again, although some decrease in activity accompanies the omission of RNAase inhibitor from reaction mixtures, this effect cannot

\section{TABLE I}

\section{EFFECTS OF SALT WASHING AND RNAase INHIBITOR ON THE ACTIVITY OF MUSCLE RIBOSOMES}

Cell-free protein synthesis was carried out as described in Materials and Methods. Reaction mixtures (50 $\mu 1)$ contained $0.14 A_{260}$ units of unwashed or 0.24 units of salt-washed ribosomes. Values in the table have been corrected by subtraction of a zero time control.

\begin{tabular}{llll}
\hline $\begin{array}{l}\text { Ribosome } \\
\text { source }\end{array}$ & $\begin{array}{l}\text { Salt } \\
\text { washing }\end{array}$ & $\begin{array}{l}\text { RNAase } \\
\text { inhibitor }\end{array}$ & $\begin{array}{l}\text { cpm [14 C]phe } \\
\text { polymerized } \\
\text { per } A_{260} \text { of } \\
\text { ribosomes }\end{array}$ \\
\hline Control & - & + & 11160 \\
8-day & - & + & 50865 \\
Control & + & + & 6191 \\
8-day & + & + & 25655 \\
Control & - & - & 8470 \\
8-day & - & - & 45259 \\
\hline
\end{tabular}

explain the difference in activity of control ribosomes as compared with ribosomes from regenerating muscle.

Binding of $\left[{ }^{3} H\right]$ phenylalanyl-tRNA by ribosomes from control and regenerating muscle

To localize the differences reported in the preceding section to a specific partial reaction of protein synthesis, the ability of ribosomes to bind $\left[{ }^{3} \mathrm{H}\right]$ phe-tRNA has been studied. As is shown in Table II, ribosomes from control muscle were not as active in phe-tRNA binding as those from regenerates when soluble enzymes were omitted from reaction mixtures. This difference in binding capacity was eliminated when soluble enzymes were present (Table II). Thus, control ribosomes have a decreased ability to support the nonenzymatic binding of at least one species of aminoacyl-tRNA under the assay conditions employed in the experiments reported here.

\section{Function of ribosomes in peptide bond formation}

The ability of muscle ribosomes to function in peptide bond formation was tested in a model

\section{TABLE II}

AMINOACYL-tRNA BINDING AND PEPTIDYLTRANSFERASE ACTIVITIES OF MUSCLE RIBOSOMES

Reactions were carried out as described in Materials and Methods. Mixtures contained $0.83 A_{260}$ units of salt-washed ribosomes, $30750 \mathrm{cpm}$ of $\left[{ }^{3} \mathrm{H}\right] \mathrm{phe}$-tRNA (A) or $73570 \mathrm{cpm}$ of $\mathrm{N}$-acetyl[ $\left.{ }^{3} \mathrm{H}\right]$ phe-tRNA (B). In all cases values have been corrrected by subtraction of a zero time control.

(A) Aminoacyl-tRNA binding

\begin{tabular}{lll}
\hline $\begin{array}{l}\text { Ribosome } \\
\text { source }\end{array}$ & $\begin{array}{l}\text { Soluble } \\
\text { enzymes }\end{array}$ & $\begin{array}{l}\text { cpm }\left[{ }^{3} \mathrm{H}\right] \text { phe-tRNA } \\
\text { bound } / A_{260} \text { ribosomes }\end{array}$ \\
\hline Control & - & 1286 \\
8-day & - & 1994 \\
Control & + & 2005 \\
8-day & + & 1914 \\
\hline
\end{tabular}

(B) Peptidyl transferase

\begin{tabular}{lc}
\hline $\begin{array}{l}\text { Ribosome } \\
\text { source }\end{array}$ & $\begin{array}{l}\left.\text { cpm } N \text {-acetyl[ }{ }^{3} \mathrm{H}\right] \text { phe-puromycin } \\
\text { formed } / A_{260} \text { ribosomes }\end{array}$ \\
\hline $\begin{array}{l}\text { Control } \\
\text { 8-day }\end{array}$ & 635 \\
\hline
\end{tabular}


system with puromycin as the acceptor for the peptidyltransferase reaction. To eliminate differences in activity which might be due to the relatively lower efficiency of control ribosomes in the nonenzymatic binding of aminoacyl-tRNA, reaction mixtures contained soluble enzymes. As is shown in Table II, ribosomes from control muscle were still significantly less active in the peptidyltransferase reaction than were ribosomes from 8 -day regenerates. This difference in activity was nearly 3-fold when calculated on the basis of the quantity of ribosomes added to the reaction mixtures.

Function of glutamyl-tRNA isoacceptors in polysomal protein synthesis

In a previous report, it was shown that changes in the relatice amounts of the muscle glutamyltRNA isoacceptors take place over the course of the regeneration process [6]. Three glutamyl-tRNA species could be separated by RPC- 5 chromatography of tRNA from control tibialis [6], and these species were also present in regenerating muscle. In control muscle, the percentages of total glutamic acid acceptor activity represented by each isoacceptor were 52.3, 8.4 and 39.3 for isoacceptors I, II and III, respectively. By 8 days following the induction of regeneration, the percentages were 54.6, 14.3 and 31.1 (see Fig. 2 for a representive RPC-5 profile of tRNAs from 8-day regenerates) and by 15 days the values were $60.4,18.2$ and 21.4 for isacceptors I, II and III. Thus, the relative amount of tRNA glu increases by about 2.5 -fold during regeneration, while the amount of $t R N A{ }_{T}^{\text {glu }}$ increases slightly and the level of tRNA declines. By 30 days following the injection of Marcaine, the levels of all three isoacceptors have returned to near-control values [6]. Since the regeneration of skeletal muscle must involve the synthesis of new contractile proteins, it seemed possible that the changes in isoacceptor patterns just described might reflect the adaptation of the muscle translational apparatus to the demand for the synthesis of those proteins. To examine this possiblity, the coding responses and the function in protein synthesis of each of the three muscle glutamyl isoacceptors has been tested.

Fig. 2 shows a typical RPC-5 profile for the glutamyl-tRNAs from 8-day regenerating muscle.

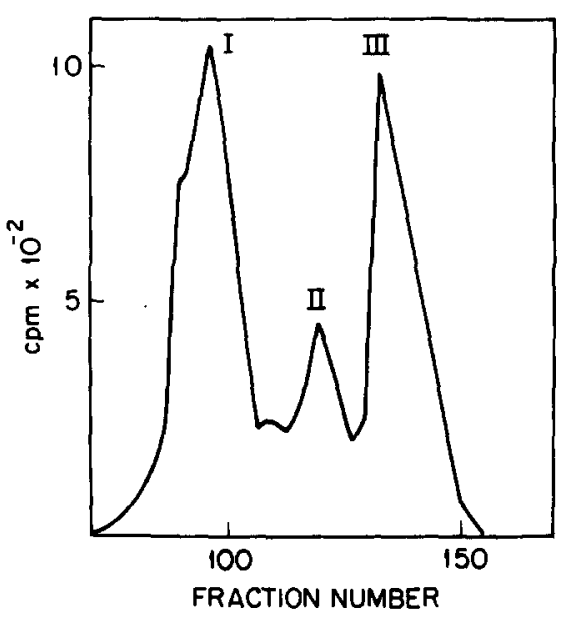

Fig. 2. RPC-5 separation of glutamyl-tRNAs from 8-day-regenerating skeletal muscle. Skeletal muscle regeneration was induced by injection of Marcaine into rat tibialis anterior as previously described [5]. Isolation and charging of tRNAs and RPC-5 chromatography were also performed as described previously [6]. Approx. $2 \cdot 10^{6} \mathrm{cpm}$ of $\left[{ }^{3} \mathrm{H}\right]$ glutamyl-tRNA were applied to the RPC-5 column, and $100-\mu 1$ aliquots of each fraction were removed and precipitated with trichloroacetic acid to generate the profile shown above.

Each isoacceptor was collected from the appropriate column fractions by ethanol precipitation and utilized for ribosome binding studies in the presence of the trinucleotide codons GAA and GAG. The results of these experiments are presented in Table III. It can be seen that tRNAII of

\section{TABLE III}

\section{CODON RESPONSES OF SKELETAL MUSCLE GLUTA- MYL-tRNAS}

$\left[{ }^{3} \mathrm{H}\right]$ Glutamyl-tRNAs were isolated from the reverse-phase column of Fig. 2 as described in the text. Binding of tRNAs to ribosomes was performed as described by Nirenberg and Leder [10] using once-salt-washed Escherichia coli MRE600 ribosomes. Reaction mixtures contained approx. 2.7 pmol of [ ${ }^{3}$ H]glutamyl-tRNA, $2.11 A_{260}$ units of ribosomes, $0.164 A_{260}$ units of GAA or $0.103 A_{260}$ units of GAG. Reaction volumes were $100 \mu \mathrm{l}$, incubation time was $20 \mathrm{~min}$ at $25^{\circ} \mathrm{C}$, and the $\mathrm{Mg}^{2+}$ concentration was $20 \mathrm{mM}$.

\begin{tabular}{llll}
\hline tRNA & \multicolumn{3}{l}{ pmol $\left[{ }^{3} \mathrm{H}\right] \mathrm{glu}-\mathrm{tRNA}$ bound in the presence of: } \\
\cline { 2 - 4 } isoacceptor & GAA & GAG & no template \\
\hline I & 0.011 & 0.101 & 0.008 \\
II & 0.098 & 0.009 & 0.006 \\
III & 0.238 & 0.016 & 0.010 \\
\hline
\end{tabular}


Fig. 1 binds preferentially to the codon GAG. while tRNA glu and tRNA glu recognize the codon GAA. This result, at least for the two major isoacceptors, I and III, is in accord with the codon assignments determined by others for mammalian glutamyl-tRNAs fractionated on RPC-5 columns [11].

The function of the glutamyl-tRNAs in protein synthesis was tested using the procedure of Carpousis et al. [12]. In their procedure, each $\left[{ }^{3} \mathrm{H}\right]$ glutamyl-tRNA is added to a polysomal reaction mixture containing total tRNA labeled with $\left[{ }^{14} \mathrm{C}\right]$ glutamic acid. The advantage of this method is that all the glutamyl isoacceptors are present simultaneously in the reaction mixture, and the translational apparatus is not forced to use one isoacceptor simply because the others are absent. The realtive utilization of each glutamyl-tRNA was calculated as described by Carpousis et al. [12], and results of these experiments are presented in Table IV along with the percentage of the total glutamic acid acceptor activity represented by each isoacceptor. It is evident from the data of Table IV that each isoacceptor is utilized for protein synthesis at a relative level which corresponds to the

\section{TABLE IV}

\section{RÉLATIVE UTILIZATION OF MUSCLE GLUTAMYL-} TRNA ISOACCEPTORS

$\left[{ }^{3} \mathrm{H}\right]$ Glutamyl-tRNAs were fractionated by reverse-phase chromatography as decribed in the legend to Fig. 2 and were used for protein synthesis in a polysomal cell-free system. Polysomes were isolated from 8-day-regenerating rat skeletal muscle as described previously [5]. Conditions for cell-free protein synthesis were as previously described [5], except that $\left[{ }^{3} \mathrm{H}\right]-$ and $\left[{ }^{14} \mathrm{C}\right]$ glutamyl-tRNAs were the sources of labeled amino acid. Reaction mixtures contained $5100 \mathrm{cpm}$ of $\left[{ }^{14} \mathrm{C}\right]$ glutamyltotal tRNA and the following amounts of the [ $\left.{ }^{3} \mathrm{H}\right]$ glutamyllabeled isoacceptors: I, $9400 \mathrm{cpm}$; II, $2160 \mathrm{cpm}$; III, $4970 \mathrm{cpm}$. Mixtures were incubated and processed as described previously [5], and precipitated proteins were solubilized with NCS solubilizer prior to liquid scintillation counting. Percent utilization was calculated according to the formula of Carpousis et al. [12].

\begin{tabular}{llcc}
\hline Isoacceptor & $\%$ of total isoacceptor activity & \multicolumn{2}{c}{$\%$ utilization } \\
\cline { 3 - 4 } & & Expt. 1 & Expt. 2 \\
\hline I & 55.9 & 56.6 & 54.4 \\
II & 12.6 & 9.1 & 12.0 \\
III & 31.6 & 34.3 & 33.6 \\
\hline
\end{tabular}

abundance of the isoacceptor in the total population.

\section{Discussion}

The data presented in this report further characterize the changes in the translational apparatus which are associated with Marcaine-induced skeletal muscle regeneration in the rat. It has been shown that ribosomes from regenerating muscle retain the increased activity which has been found for polysomes (as compared with controls) and that this increased activity is not abolished by salt washing of the ribosomes. Further, the increased activity appears to be due to a relatively higher efficiency of ribosomes from regenerating muscle in the nonenzymatic binding of aminoacyl-tRNA to those ribosomes and in the efficiency of the peptidyltransferase reaction in regenerates. It is not clear at thise time whether the molecular modifications responsible for the observed effects result in a decrease in the activity of control ribosomes (in which case the modification would presumably be reversed during the regeneration process) or whether 'normal' ribosomes are modified during regeneration so that they become more active. It is also not certain what ribosomal components(s) may be altered to effect the changes which have been described above. That these changes affect the ability of ribosomes to bind tRNAs and catalyze peptide bond formation would seem to implicate ribosomal proteins in the observed phenomena. Indeed, there is evidence in prokaryotes, at least, that some of the proteins involved in the recognition and binding of aminoacyl-tRNA are also involved in peptide bond formation $[13,14]$.

Ribosomal proteins from control and regenerating muscle have been examined by one-dimensional polyacrylamide gel electrophoresis and no significant differences have been observed (unpublished results). One likely way in which muscle ribosomes might be chemically modified would involve phosphorylation of specific ribosomal proteins. Ribosome phosphorylation has been shown to affect ribosome activity, and both decreases and increases in that activity have been observed to result from protein phosphorylation [15]. Changes in protein charge due to phosphorylation would 
probably not be detectable on one-dimensional polyacrylamide gels. Experiments are in progress, therefore, to examine the ribosomal proteins from control and regenerating muscle by two-dimensional electrophoresis.

With regard to the funciton of the glutamyltRNA isoacceptors in muscle protein synthesis, there is accumulating evidence that, at least in some systems, changes in tRNA isoacceptor profiles may represent an adaptation of the cellular translational apparatus to facilitate the synthesis of new proteins. Thus, it has been reported that one of two glycyl-tRNAs is preferentially used for fibroin synthesis in the silkworm [16] and that a specific glycyl-tRNA is preferentially used for collagen synthesis in chick embryos [17]. In contrast, Smith, et al. [18] have shown that the lysyl-tRNA which increases in relative amount in rapidly dividing mammalian cells is not used preferentially for the translation of globin mRNA. This lysyltRNA has been shown to be a hypomodified form of one of the major lysyl isoacceptors [19]. The situation described above for the muscle glutamyl-tRNAs seems akin to that found for mammalian lysyl-tRNA. It seems possible that tRNA II is a hypomodified form of one of the major isoacceptors, perhaps tRNA glu, since the relative amount of tRNA III decreases in regenerating muscle and both isoacceptors II and III recognize the codon GAA. If this is so, the results presented above would be consistent with those of others which indicate that fully modified isoacceptors are usually utilized for protein synthesis in preference to hypomodified forms $[18,20]$.

\section{Acknowledgement}

This research was supported by grant number PCM-8216129 from the National Science Foundation.

\section{References}

1 Hall-Craggs, E.C.B. (1974) Exp. Neurol. 43, 349-358

2 Carlson, B.M. and Gutmann, E. (1975) Pflugers Arch. 353, 227-239

3 Benoit, P.W. and Belt, W.D. (1970) J. Anat. 107, 547-556

4 Jirmanova, I and Thesleff, S. (1972) Z. Zellforsch. 131, $77-97$

5 Jones, G.H. (1982) Muscle and Nerve 5, 281-290

6 Jones, G.H. (1983) Biochim. Biophys. Acta. 741, 333-340

7 Jones, G.H. (1975) Arch. Biochem. Biophys. 170, 409-416

8 Jones, G.H. (1975) J. Bacteriol. 124, 364-372

9 Haenni, A.-L. and Chapeville, F. (1966) Biochim. Biophys. Acta $114,135-148$

10 Nirenberg, M. and Leder, P. (1964) Science 145, 1399-1407

11 Hatfield, D., Matthews, C.R. and Rice, M. (1979) Biochim. Biophys. Acta 564, 414-423

12 Carpousis, A., Christner, P. and Rosenbloom, J. (1977) J. Biol. Chem. 252, 8023-8026

13 Moore, V.G., Atchison, R.E., Thomas, G., Morgan, M. and Noller, H.F. (1975) Proc. Natl. Acad. Sci. USA 72, 884-848

14 Nierhaus, D. and Nierhaus, K.H. (1973) Proc. Natl. Acad. Sci. USA 70, 2224-2228

15 Burkhard, S.J. and Traugh, J.A. (1983) J. Biol. Chem. 258, 14003-14008

16 Chen, G.S. and Siddiqui, A.Q. (1974) Arch. Biochem. Biophys. 161, 109-117

17 Carpousis, A., Christner, P. and Rosenbloom, J. (1977) J. Biol. Chem. 252, 2447-2449

18 Smith, D.W.E., McNamara, A.L., Rice, M. and Hatfield, D.L. (1981) J. Biol. Chem. 256, 10033-10036

19 Raba, M., Limburg, K., Burghagen, M., Katze, J.R., Simsek, M., Heckman, J.E., FajBhandary, U.L. and Gross, H.J. (1979) Eur. J. Biochem. 97, 305-318

20 Gefter, M.L. and Russell, R.L. (1969) J. Mol. Biol. 39, 145-157 